\title{
Reflexões Conceituais para a Delimitação de um Parque Urbano para Rio Claro (SP)
}

\section{Conceptual Reflections for the Delimitation of an Urban Park for Rio Claro (SP)}

\section{SARTI, A. C.}

Bacharel em Turismo, Mestre em Conservação e Manejo de Recursos, Área de Concentração Gestão Integrada de Recursos pelo CEA - UNESP/Rio Claro. Coordenador do Curso de Bacharelado em Turismo da UNIMEP.

\section{Rodovia do Açúcar, Km 156, CEP 13.400-911, Piracicaba - SP. e-mail: acasarti@unimep.br}

\section{RESUMO}

O presente artigo tem por finalidade expor aspectos da pesquisa que teve como objetivo principal propor critérios para a delimitação de um parque com funções urbanas, instalado na seção leste do município de Rio Claro (SP), em área da bacia hidrográfica do Ribeirão Claro. O estudo envolveu: análise de informações geológicogeotécnicas; análise e interpretação de aerofotos para identificação de fragmentos de mata nativa; roteiro expedito através de sobrevôo e incursões nos bairros da área-piloto; contextualização da dinâmica da ocupação do espaço e o levantamento da evolução do objeto urbano /parque/. Para efeito de aplicação de instrumentos de pesquisa, foi delimitada uma área-piloto abrangendo bairros da zona nordeste da cidade, enquadrada pelos estudos específicos da área de geotecnia como altamente impactada ou de maior fragilidade. Nesse sítio foram feitos levantamentos de campo com a aplicação de questionários, visando à obtenção de dados sobre o perfil da população e a existência e uso dos espaços livres de uso público. Utilizando metodologia de abordagem sistêmica na orientação do espaço hologrâmico, foi proposta a criação de uma Área de Proteção Ambiental - APA municipal abrangendo os limites da bacia, e realizada uma compartimentação com base nos atributos da paisagem, definindo-se os setores: Ajapi, no alto curso; São José e Rio Claro, no médio curso, e Santa Gertrudes, no baixo curso. Foram sugeridos, ainda, núcleos de prestação de serviço, reservando-se ao diálogo e à negociação com a comunidade a definição de seu escopo gerencial e suas funções na 
administração do parque proposto.

Palavras-chave: parque, área de uso público, Área de Proteção Ambiental, lazer, antropologia urbana.

\section{ABSTRACT}

The present article aims at showing the aspects of a research with the following main objective: to propose a criteria to delimit the park with urban functions located in the eastern part of Rio Claro city (SP), in an area of the hydrographic basin of Ribeirão Claro. The study involved geological-geotechnichal analyses; photographs analyses and interpretation in order to identify native forest fragments, as well as aerial guide and incursions in neighborhoods of the pilot area; it also included a contextualization about the dynamic of occupation and surveying the evolution of urban object park. For the application of research instruments a pilot area embracing the neighborhoods of northeast part of the city was defined, based on specific geotechnichal studies, which indicated high impact or displaying more fragility. In this site, field surveys using questionnaires were made to obtain data about the outline of the population and the existence and utilization of leisure areas for public use. Relaying on the systematic approach methodology in the orientation of a hologramic space, was proposed the creation of a County Environmental Protected Area. The division of this area was based on the landscape characteristics, defining according to sectors: Ajapi, at the high level, São José and Rio Claro, at the middle level and Santa Gertrudes at the lower level of the river. Moreover, suggestions were mode for technical assistance to service nucleuses, leaving both the definition of its management purpose as well as the functions in the administration of the proposed park open to dialogue and negotiation with the community.

Key Words: Public Use Area; Environmental Protected Area; Leisure; Urban Anthropology.

\section{INTRODUÇÃO}

O estilo de vida da sociedade industrial pós-moderna impõe necessidades uniformes a comunidades diferentes. Dessa forma, a manifestação da necessidade de áreas livres de uso público se impõe a habitantes de cidades de diferentes perfis.

Através da pesquisa, pode-se constatar que a criação e implantação de áreas verdes têm tido por finalidade precípua harmonizar o desenho urbano às áreas de risco, áreas impactadas ou degradadas, incorporando-as, obedientes à lógica capitalista de produção e apropriação do espaço. Nesse processo, nem sempre as comunidades são 
acionadas e estimuladas a participar, recebendo os benefícios como dádiva do Estado e os malefícios como parte do preço a pagar pelo acesso àqueles.

Municípios de pequeno e médio porte, a maioria dentre os que compõem a rede de cidades que, do interior de São Paulo, incorpora outras do sul de Minas Gerais, do norte do Paraná e do sul do Mato Grosso, podem tirar proveito da legislação existente e concernente à proteção de atributos da paisagem, podendo viabilizar a implantação de parques públicos com baixo investimento direto, partindo do entendimento e da crítica aos processos complexos e dinâmicos de construção e modelagem da paisagem.

Para que esta tarefa logre êxito, propõe-se um tratamento metodológico que se denominou espaço hologrâmico (MORIN, 1997).

\section{Aproximação com a metodologia} SANTOS (1999).

O espaço é o mais interdisciplinar dos objetos concretos, no dizer de

Assim compreendendo, para encontrar explicações a respeito de como a sociedade vem interferindo na natureza, ao longo dos processos históricos, optou-se por uma abordagem do problema que pudesse oferecer oportunidade de discussão ampla, compartilhando do pensamento que preconiza a construção do conhecimento baseado na complexidade que se nos oferecem os fenômenos da natureza.

Partindo do objetivo principal, os estudos realizados conduziram à conclusão de que o oferecimento de critérios com os quais delimitar um parque peri-urbano para a cidade de Rio Claro (SP) enseja a oportunidade de discutir os processos pelos quais a sociedade moderna se sente cada vez mais premida pela necessidade de espaços abertos nas cidades, e as exigências que se vêm fazendo para equipá-las com esses objetos. A construção histórica dessa necessidade, e dos significados a ela acoplados, remonta a vários séculos em culturas muito distintas da brasileira que, paradoxalmente, a esses valores e paradigmas se apega para com eles pautar a ação.

Considerou-se a aplicabilidade da abordagem sistêmica, evoluindo segundo a proposta de MORIN (1997) para uma visão complexa, denominada na pesquisa espaço hologrâmico (Figura 1). Sem perder ou desconsiderar o conhecimento produzido por outras formas de pesquisa, assim como também concebeu Koestler para sua noção de holon, o exercício de olhar a realidade, articulando ao mesmo tempo diferentes escalas e dimensões, proporcionou associar fenômenos e fatos para estabelecer um nexo entre estes. Tal nexo é a possibilidade de materializar a proposta, aproximando acontecimentos do "futuro-já" aos acontecimentos de um passado remoto, mas, ambos, sustentando a realidade do presente. 
Portanto, elencar variáveis com as quais riscar nos mapas contornos arredondados chamados parques - lineares ou não - , que no dizer de JACOBS (2000) mais parecem peças de estamparia, infelizmente não tem tido o condão de resolver os problemas evidenciados com a questão da disponibilização de áreas livres, abertas ao uso público, numa sociedade que vem caminhando firme e convictamente no sentido de renegar a razão pública e o espaço público em obediência a um ditame, para ela, extremamente forte e sedutor, de privilegiar as atividades privadas.

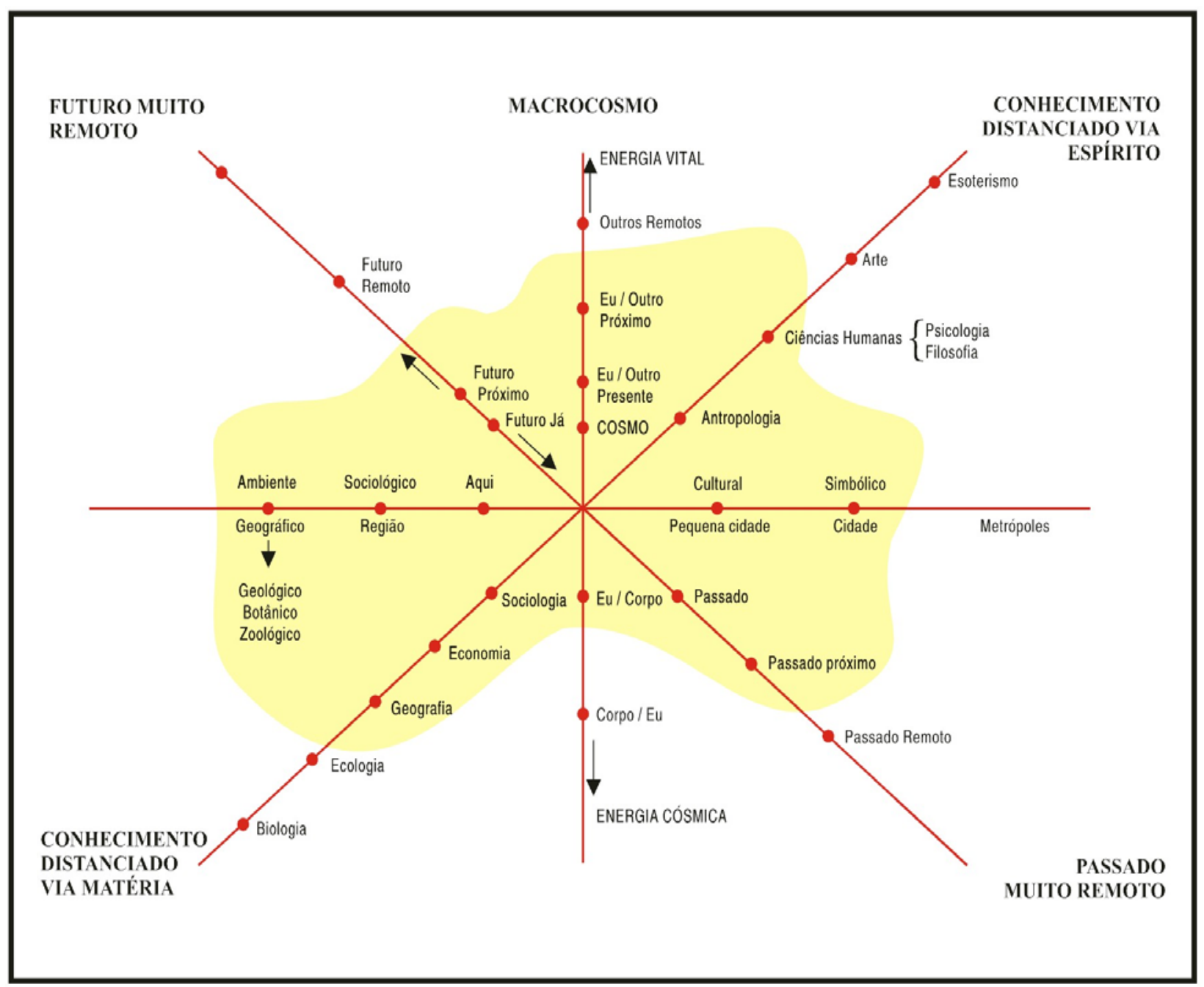

Figura 1 - Representação gráfica do espaço hologrâmico.

Elaborado a partir de MORIN (1997), articula diferentes planos e áreas do conhecimento que se entrecruzam no movimento e criam uma zona de domínio do pensamento a partir do ponto de vista do observador.

\section{A cidade e o espaço público}

A formação do espaço público se confunde com a criação do espaço urbano. Um não pode ser identificado sem o outro, criando uma dicotomia e bipolaridade cuja dinâmica, ao longo do tempo, molda e conforma a definição do que é urbano e do que é não-urbano, interferindo no desenho das cidades, nas formas de criação e uso dos espaços 
livres, na construção de códigos com os quais expressar a visão predominante.

Para Aristóteles, "uma cidade é um certo número de cidadãos (...) que possui [em] a faculdade de intervir nas funções deliberativa e judicial da mesma (...)". Essa concepção se adapta à cidade-estado grega por contemplar uma dimensão política, em que a cidade é o Estado e o Estado é a cidade. É no espaço da ágora que essas dimensões se encontram para fazer prevalecer a polis.

$\mathrm{Na}$ democracia romana, a consagração da praça como espaço público no direito é uma evolução manifesta nas Institutas de Justiniano. O bem público "do povo" está alicerçado na concepção de que o publicus romano indicava pertencer ao Populus, fazendo coincidir o pertencer e o uso. Ao Estado compete intervir nos bens de uso comum (res communes omnium) "através do poder de polícia, com a finalidade de que sejam respeitadas as regras de convivência" gerindo-os, não se transformando em proprietário. É a civitas latina (MACHADO, 1998).

Para Afonso, o Sábio, cidade é definida como todo lugar circundado por muralhas, com os arrabaldes e edifícios que aquelas defendem. Trata-se da cidade medieval que não se concebe sem muros que as defendam das ameaças que vêm do exterior (GOITIA, 1996).

No entender de ORTEGA Y GASSET, o homem constrói a cidade na busca de uma diferenciação com a natureza, em que o elemento fundamental é a praça. Diz ele: "A urbe é, antes de mais o seguinte: praceta, ágora, local para conversa, discussão, eloqüência, política". Sua concepção é a de uma cidade política, que conversa e que faz do espaço público um lugar para a expressão da cidadania e que, ao tê-lo diminuído ou desfigurado, faz decliná-la, empobrece sua dimensão, abre terreno para a corrosão da identidade e da estima sociais (GOITIA, 1996).

Para o homem latinizado e mediterrâneo, o essencial e definitivo da cidade será a praça e o que esta significa, a tal ponto que, quando esta falta, não entende que possa chamar cidade a uma aglomeração urbana. Seu modelo de cidade se aproxima do conceito towns, que se refere a um ambiente fechado, parte do campo transformado em casa ou granja. Não é um conceito político mas, antes, um conceito agrário (GOITIA, 1996).

O que possibilita diferenciação de uma cultura ou de um momento para outro são os usos do espaço público, entendidos como manifestação do usuário ao se relacionar com o ambiente contextualizado. "Não se pode pensar ruas, praças, avenidas, passeios, casas ou prédios como elementos autônomos (...), configuram-se como uma realidade sígnica que informa sobre seu próprio objeto: isto é, o contexto.(...) O uso é uma leitura da cidade na relação humana das suas correlações contextuais. Logo, uma praça só encontra seu espaço contextual no momento em que é flagrada numa seleção de usos que 
lhe atribui significado. O usuário processa a leitura do mutante espaço contextual, ao mesmo tempo em que nele inscreve sua linguagem: o uso que flagra e é flagrado na cidade" (FERRARA, 1981).

A praça pública, no fim da Idade Média e no Renascimento, "era o ponto de convergência de tudo que não era oficial, de certa forma gozava de um direito de 'extraterritorialidade' no mundo da ordem e da ideologia oficiais, e o povo aí tinha sempre a última palavra", segundo BAKTIN (1999). Entenda-se o que não era oficial por todas as manifestações que contradissessem o discurso oficial e as rígidas regras de etiqueta, polidez e comunicação hierárquica em casa, nos palácios, na igreja, nas solenidades. "A praça pública em festa reunia um número considerável de gêneros e de formas maiores e menores impregnados de uma sensação única não-oficial, do mundo" (BAKTIN,1999).

Durante o Renascimento, o ideal de cidade concebia um desenho racionalizado, adotando estruturas lógicas que simbolizavam uma nova ordem política. A cidade de então incorpora, na proposição urbanística, "tratados de política" que "acentuam a necessidade de processar uma racionalização da cidade tanto em seu plano legislativo como arquitetônico". Assim, "a cidade medieval, crescida desordenadamente em torno de si mesma, com seus edifícios concentrados ao longo de estreitas e tortuosas vias, deverá ser substituída por uma nova cidade planificada de acordo com o desenho racional" (SEGAWA, 1996).

A cidade barroca, no século XVIII, de caráter senhorial e eminentemente consumidor, era o espaço onde reinava o luxo e que estava na origem das grandes cidades do ocidente, antes da industrialização (GOITIA, 1996).

O crescimento das cidades em função do êxodo rural cria condições de vida totalmente insalubres e inseguras. Quando a Rainha Vitória ascendeu ao trono, em 1836, havia 6 cidades, inclusive Londres, com mais de 100 mil habitantes. Em 1901, quando faleceu, eram cerca de 25 . De fato, foi pela reunião de inúmeros fatores favoráveis que se instalou na Inglaterra do século XIX a produção em escala, iniciando-se pela indústria têxtil. "Manchester, a primeira cidade industrial, tinha em 1760 entre trinta e quarenta mil habitantes, cresceu em 1800, graças à utilização da máquina a vapor, até alcançar setenta mil habitantes, dez mil dos quais eram emigrantes irlandeses atraídos pelo desenvolvimento industrial da grande cidade. Em 1830, a inauguração do 'Manchester and Liverpool Railway' originou outro considerável crescimento urbano. À volta de 1850, a população já era de cerca de quatrocentos mil habitantes" (GOITIA, 1996).

Para desmistificar a era vitoriana como detentora de um charme com o qual a sociedade inglesa era rotulada, Alexis de Tocqueville (1805-1859), em visita a Manchester, observou: "[n]essas habitações miseráveis, há fileiras de porões a que se chega por um corredor subterrâneo: 12 a 15 seres humanos estão atulhados em cada um 
desses buracos úmidos e repugnantes(...). Desse esgoto nojento flui a maior fonte da indústria humana que fertiliza o mundo. Dessa cloaca fétida flui ouro puro. Aqui a humanidade alcança seu mais alto desenvolvimento e a mais crua brutalidade; aqui a civilização faz seus milagres e o homem civilizado regride à selvageria" (SEVCENKO, 2000).

As grandes cidades industriais daquela época, assim como nas grandes e médias cidades de hoje, tornavam-se viáveis, do ponto de vista econômico, pela possibilidade de manter um grande contingente populacional disponível para exercer o papel de provedor de mão-de-obra barata, sob absoluto controle do empregador capitalista.

Nessas condições, despreparadas para abrigar a população que crescia rápida e exponencialmente, as cidades têm o espaço organizado para abrigar o maior número possível de pessoas, mesmo que em condições insalubres e desumanas. As fábricas ocupavam todos os espaços que desejavam segundo seu interesse de produção, avançando sobre bosques, jazidas, margens dos rios e paisagens que deveriam ser preservadas. Não era de estranhar que, desse modo, os índices de mortalidade crescessem assustadoramente. Em Nova Iorque, o índice de mortalidade infantil em 1810 era de 120 a 145 por 1000 nascimentos; em 1850, chegou a 180; em 1860, a 220, e em 1870, a 260, segundo GOITIA (1996).

\section{Salubrismo}

O ambiente urbano, marcado pelo desconforto da grande maioria de seus habitantes, aglomerados em bairros desprovidos de infra-estrutura e submetidos a uma política de máximo aproveitamento do espaço tanto público como privado, consolidava a concepção de insalubridade.

As cidades, dominadas pela poluição gerada com a queima de carvão para o aquecimento e para a movimentação das máquinas, tornavam-se ambientes vistos e interpretados como impróprios para a vida, ao contrário do que se interpretava da vida no campo.

Dessa contraposição estética, filosófica e quase religiosa, desenvolvia-se a idéia de associação de melhores condições sanitárias, com a presença de árvores e espaços onde elas pudessem ser plantadas e cultivadas. Plantar árvores passava a ser uma recomendação de valorização social e política. Associava-se a presença de árvores à purificação do ar e a criação de parques públicos ao combate das causas das epidemias. Segundo essa concepção, árvores e parques tornariam melhor o ar da cidade e proporcionaria maior incidência de luz natural. 
Pela mesma lógica, passavam a ser considerados insalubres as áreas alagadas, brejos e margens de rios e córregos, merecendo a ação que, amparada por essa concepção amplamente aceita, promovia o aterramento, a retificação, o represamento, a drenagem, o desvio, o aprofundamento ou assoreamento de canais, a substituição ou até mesmo a supressão da vegetação.

A essa concepção deu-se o nome de salubrismo, que está presente nos discursos e arrazoados oficiais para a implantação de praças, jardins públicos, parques de diferentes dimensões e finalidades, passando a fazer parte do imaginário popular quando acionado para explicar ou dar sua percepção do ambiente natural ou do ambiente urbano dotado de elementos naturais (SEGAWA, 1996; THOMAS, 1996).

As necessidades decorrentes do caos urbano já consolidado criaram as condições políticas para que os parques fossem concebidos, projetados como objetos urbanos aos quais se associava uma função de salubridade, em primeiro plano, e uma decorrente função de controle social, subsidiariamente.

O jardim e o parque públicos, criações marcantes na urbanização européia a partir do século XVI, ergueram-se sobre a tradição da praça pública - o espaço de domínio público por excelência - e não negaram em sua formulação esse envolvimento mitológico e estético com a natureza. As praças ancestrais perderam seu caráter de lugar onde a espontaneidade se manifestava. Em oposição, difundia-se o jardim, retirado da esfera privada para a esfera pública, como um espaço onde as pessoas vêem outras e querem ser vistas, obedecendo a regras e formalidades de comportamento. Os espaços públicos concebidos na forma de parques urbanos, destinados inicialmente como áreas para deleite da elite e exibição do poder econômico e político bem como para demonstrar a presença do Estado, passaram a representar lugares de maior proximidade com a natureza, uma natureza dotada de novo significado, artificializada ou apenas como cenário para uma situação idealizada, distante, ameaçada e identificada, cada dia mais, como enobrecedora. As associações de conteúdos e significados vai tornou possível estabelecer um nexo entre ascensão do Estado, aumento do número de habitantes nas cidades, perda da qualidade de vida, queda nas condições de segurança, medo das elites e necessidades do Estado de se fazer presente e de ele próprio produzir o cidadão (FOUCAULT, 2000).

\section{O signo}

A questão suscitada pela existência de espaços livres de uso público nos domínios do sítio urbano, a possibilidade e a qualidade do acesso e os usos que a população dá, ou a legislação prevê, tem mantido acesa uma controvérsia entre estudiosos brasileiros. Ao que se percebe das inúmeras manifestações, há uma busca para uma 
categorização ou sistematização, no mínimo, com o intuito de fixar um significado ou de estabelecer uma pretendida nomenclatura aceita e compartilhada pela comunidade científica.

Há uma intensa discussão sobre categorização, tipologia, disponibilidade de áreas livres de uso público, animada pela importância que estas passam a ter na concepção de cidade após a Revolução Industrial, consagrada pelos estudiosos e difundida junto ao público, implicando o reconhecimento, por parte dos cidadãos, das possibilidades de uso, previstos ou não na origem legal ou institucional das áreas. Esse componente político tem grande influência em todos os instantes do processo de decisão, seja ele público ou privado, fazendo estar presente a todo instante na literatura específica a preocupação com a elaboração de índices e parâmetros confiáveis com os quais trabalhar.

No entanto, a diversidade de soluções encontradas pelas administrações públicas e pela própria população, quando resolve tomar a iniciativa de usar o espaço livre espontaneamente, são os motivos de inquietação e, ao mesmo tempo, fonte da riqueza de elementos para os quais os pesquisadores devem lançar seu olhar com o objetivo de melhor conhecer a realidade e encontrar novas soluções adequadas ao ambiente cultural e social brasileiros. Nesse sentido, os autores e divulgadores dos dados da Tabela 1 afirmam que eles não devem ser entendidos como uma fórmula acabada, mas como um referencial útil através do qual dialogar com os fatos da realidade brasileira.

Tabela 1 - Categorias e sugestão de índices urbanísticos para espaços livres urbanos

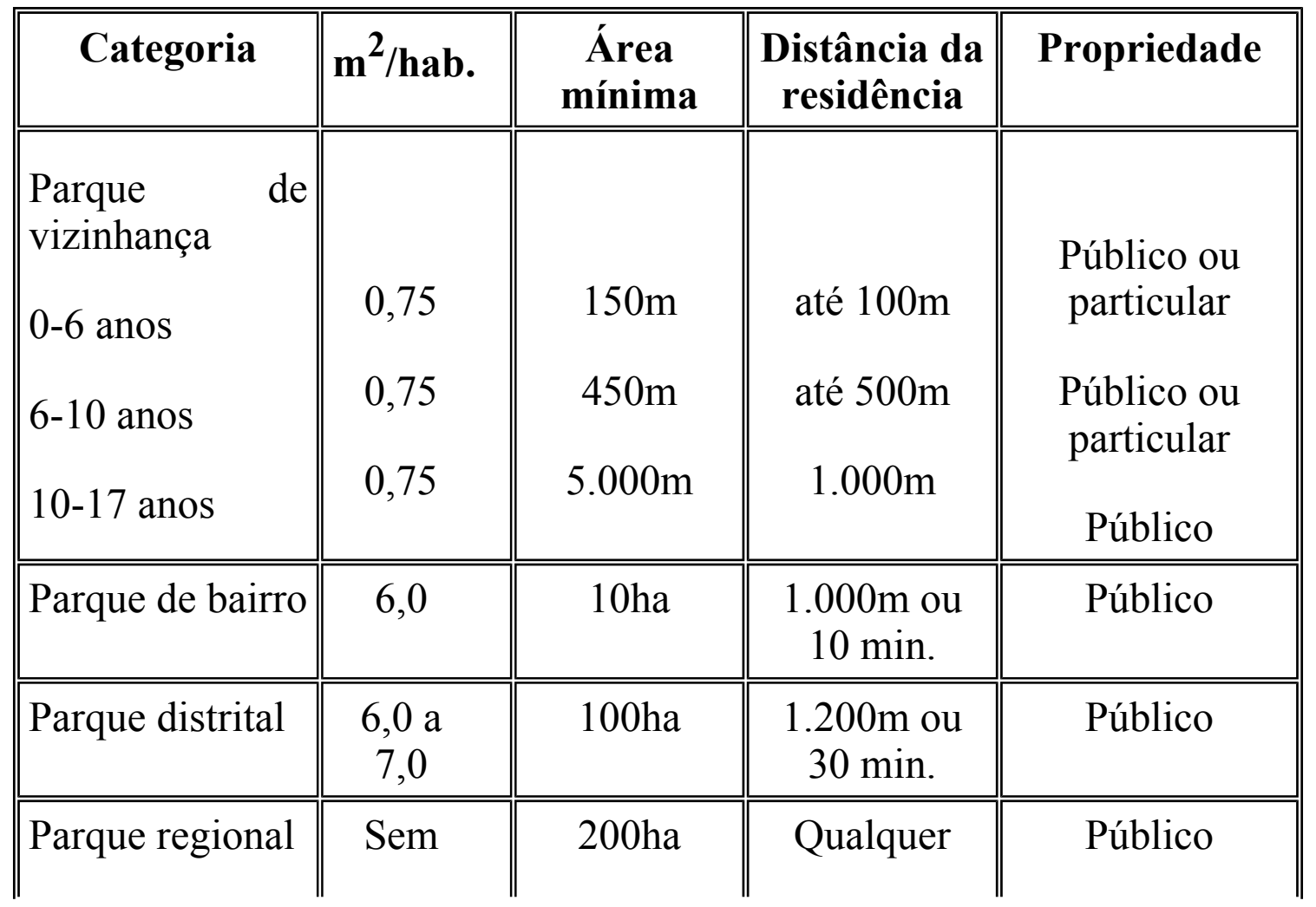




\begin{tabular}{|c|c|c|c|c|}
\hline & referência & com água & $\begin{array}{l}\text { parte da } \\
\text { cidade }\end{array}$ & \\
\hline Cemitério & 4,5 & $\mathrm{~S} /$ ref. & $\begin{array}{c}\text { Sem } \\
\text { referência }\end{array}$ & $\begin{array}{l}\text { Público ou } \\
\text { particular }\end{array}$ \\
\hline $\begin{array}{l}\text { Área para } \\
\text { esporte }\end{array}$ & 5,5 & $\begin{array}{c}3- \\
5 \text { ha/ } 15.000 \\
\text { hab. }\end{array}$ & $\begin{array}{l}\text { Perto de } \\
\text { escola }\end{array}$ & $\begin{array}{l}\text { Público ou } \\
\text { particular }\end{array}$ \\
\hline Balneário & 1,0 & $0,2 / 2,0$ ha & $\begin{array}{l}\text { Perto de } \\
\text { escola }\end{array}$ & $\begin{array}{l}\text { Público ou } \\
\text { particular }\end{array}$ \\
\hline $\begin{array}{l}\text { Horta } \\
\text { comunitária }\end{array}$ & 12,0 & $300 \mathrm{~m}^{2}$ & $\begin{array}{c}\text { Sem } \\
\text { referência }\end{array}$ & $\begin{array}{l}\text { Público ou } \\
\text { particular }\end{array}$ \\
\hline Verde viário & S/ ref. & S/ ref. & $\begin{array}{c}\text { Junto ao } \\
\text { sistema } \\
\text { viário }\end{array}$ & Público \\
\hline
\end{tabular}

Fonte: CAVALHEIRO \& DEL PICCHIA, 1992.

Tais categorias e especificações estão de acordo com a concepção de função vista por urbanistas. Segundo MAGNOLI (1986), "a apropriação dos espaços livres pelo homem para suas necessidades e atividades é criada em níveis locais, setoriais, urbanos, metropolitanos, sub-regionais e regionais em função da proximidade espacial. A proximidade espacial, movimento, exige permeabilidade entre os espaços e por meios diversificados e amplos de locomoção a distribuição de espaços livres para serem apropriados pelo homem (sistema de parques) fica vinculada às maneiras de acessos disponíveis em cada uma das escalas de urbanização, e à freqüência dos usuários. Freqüência, utilização, apropriação em sentido amplo diz respeito à duração e periodicidade de tempo disponível. Isto traz esquematicamente (e ainda que grosseiramente) a usos diários, semanais, de feriados, de férias curtas ou prolongadas. (...) $\mathrm{O}$ atendimento do cidadão nas várias escalas da urbanização e a diversidade da apropriação em atividades variadas, diversificadas, específicas ou não, 'ativas', 'passivas', ou para todos os cidadãos, em idade, sexo, isolados ou em grupos, leva à distribuição de espaços diversificados no interior, na periferia e no exterior da mancha urbana".

Outro aspecto relevante muito considerado pelas análises, explícita ou implicitamente, é o que se refere à capacidade do meio físico, destacando-se a presença de características topográficas, climáticas ou geográficas, indicando os pontos críticos e a melhor aptidão para o oferecimento de atividades ao ar livre.

Evidencia-se a construção histórica e social dos conteúdos que se vinculam 
ao signo /parque/. Eles são resultado da elaboração histórica e, contextualizados na e pela cidade, exprimem a forma pela qual a sociedade humana elabora novos usos e agrega novos significados, comprometendo a possibilidade de estabelecer categorizações, generalizações, morfologias e estruturas. "Como processo em constante convergência e conversão de significados, o uso não se amolda a normas, estatutos ou códigos, mas é, antes, fala subversiva e marginal pela maneira como preenche o espaço urbano de inusitados significados e gera a impresivibilidade de outros usos; por ser um processo intersemiótico, o uso resiste a uma síntese que é operação cabível no mundo linear, lógico, seqüencial; ao contrário, o uso é feito de lampejos e intuições que não se encadeiam numa relação de antecedente e conseqüente, causa e efeito, condição e condicionado. Logo, apenas no terreno do inusitado pode-se prever uma geração de usos e, apenas didaticamente, pode-se pensar numa morfologia do uso urbano como uma protocategorização do ambiente urbano" (FERRARA, 1981).

Como projeto resultante de processos de interpretação das condições locais ou não, o parque se configura num objeto que assume múltiplo significado e, muitas vezes, o seu conteúdo "segundo" pode extrapolar o seu conteúdo "primeiro". Como objeto arquitetônico, pode ser estudado como um sistema de comunicações que, em primeiro lugar, quer expressar a função original a que se destina e, em segundo, expressar a ideologia da sociedade que o engendra quando tem características sígnicas mais claras como dotar a área com certos equipamentos que predeterminam um uso, um tempo, um procedimento, um comportamento, domínio de habilidades, idade, sexo, classe social e muitas outras variáveis. Nesse sentido, destaca-se a solução de Frederick Law Olmsted (1822-1903) para o Central Park de New York (EUA), onde "imaginou uma solução brilhante, corajosa, antipastoral e americana. Férias de verão para quem podia custeá-las já significavam os ermos dos Adirondacks ou das White Mountains de New Hampshire. Para as 'centenas de milhares de trabalhadores cansados', entretanto, que não dispunham nem de tempo nem de recursos para desfrutar tais prazeres, devia-se preservar uma parte da natureza selvagem original de Nova York" (SCHAMA, 1996).

\section{Bacia hidrográfica}

A escolha da abordagem espacial da questão por meio da bacia hidrográfica é outro elemento importante, na medida em que reforça a concepção de que esse critério oferece as respostas adequadas para o tratamento de temas diversos, como aspectos físicos, bióticos e noóticos. Há uma longa evolução, também, desse princípio, ressaltando-se que a consagração da concepção de natureza para meio ambiente dá consistência ao critério bacia hidrográfica pela possibilidade de articulação de partes que se entrecruzam em fluxos dinâmicos. Além disso, a água como recurso natural, visivelmente em xeque pelo modelo de desenvolvimento adotado, exige posturas inovadoras e até ousadas ante a possibilidade nem um pouco remota de escassez. Mesmo 
na bacia do Ribeirão Claro, ante a situação apresentada, a água merece tratamento prioritário, articulado a outros recursos e medidas. Será impossível para uma sociedade como a rio-clarense, ou para qualquer outra, tratar de seu rio e, por conseqüência, de seus cidadãos, se olhar para um problema e descuidar de outros. O que o critério bacia hidrográfica nos coloca preambularmente é a forma de ver: ampla, complexa, arejada, fluida, desafiadora; que vê a unidade proporcionada pelos afluentes, mas que permite investigar as suas particularidades. O princípio de gestão dos recursos hídricos adotado pela legislação brasileira, correspondendo ao ideário formulado a partir das conferências internacionais e da mudança de visão da opinião pública acerca da natureza, contempla o princípio de uso múltiplo, com gestão compartilhada. Pela norma, a água é um bem dominial; (...) o uso não pode acarretar poluição ou conspurcação; o uso não pode esgotar o próprio recurso e a sua utilização será feita mediante licença dada pelo Poder Público (MACHADO, 1998).

\section{A definição do parque}

Uma questão que se tornou crucial foi avaliar o impacto causado pelas sucessivas ocupações da bacia do Ribeirão Claro. A presença do homem é registrada desde a pré-história, como atestam os sítios arqueológicos líticos ou cerâmicos, possibilitando inferir que eram populações nômades de caçadores e coletores da tradição tupi-guarani (SILVA, 1967). A cobertura de floresta estacional semidecidual permaneceu intocada até o início do século XVIII, quando o colonizador esteve presente nessas áreas, sucedendo aos bandeirantes caçadores de índios, genocidas.

Em seguida, deu-se início à instalação de pequenas unidades produtoras de açúcar, tocadas por pequenos proprietários que avançavam gradativamente sobre a floresta. Com a importância do produto na Europa, a empresa ganhou força ao atingir as terras da Depressão Periférica Paulista e, em conseqüência dos incentivos da Coroa, instalaram-se as sesmarias. A região de Rio Claro era inteiramente dedicada a essa atividade que, nem bem havia se afirmado, foi rapidamente substituída pelo café (DEAN, 1977).

A cultura cafeeira dominou todos os espaços e fez crescer a cidade e sua importância política. Concentra-se tal poder econômico que possibilitou aos fazendeiros do vale do Corumbataí dar origem ao único empreendimento ferroviário do gênero.

Toda essa pujança foi sustentada pelo solo favorável à cultura cafeeira, solo esse derivado de rochas magmáticas de caráter básico (diabásio e basalto), e enriquecido pela camada de húmus acumulada pelos milhares de anos de deposição de serapilheira.

Passado o ciclo cafeeiro, com as propriedades em crise, o solo de muitas delas exaurido, instalou-se o ciclo seguinte, dedicado à criação de gado, leiteiro e de 
corte, ao lado de outras lavouras. A partir da década de 1950, a cana-de-açúcar voltou a ser cultivada para dominar a paisagem de forma significativa.

A Tabela 2, permite visualizar os atributos da paisagem na bacia do Ribeirão Claro, por setores, e avaliar a variedade e a intensidade das transformações ocorridas no uso do solo e do espaço em função dos processos econômicos, políticos, sociais e culturais. A Figura 2, possibilita reconhecer os limites, o zoneamento, os atrativos e a estrutura do parque.

\section{Aspecto social}

Com relação aos aspectos sociais, tem-se como defensável que a população da área-piloto está em fase de acomodação e transição.

Em acomodação pelo fato de os assentamentos mais recentes serem provenientes de planos habitacionais desenvolvidos em âmbito municipal, impelindo para a região pessoas de diferentes matizes econômicos, culturais e sociais. A construção da casa, mesmo que em dissonância com a casa sonhada, está sendo feita e moldada às exigências dos bairros que vão criando.

Áreas de lazer, muito poucas quando decorrentes de ação do poder público, são criadas sobre as áreas livres, conforme as necessidades e os usos mais imprevistos.

Premidos pela necessidade de sobrevivência, e acuados por jornadas de trabalho em turnos, a população falta de prática e de perspectiva associativa, empobrecendo as relações sociais e tornando cada vez mais distantes pessoas que têm muito em comum mas não se encontram. É uma vida de trabalho ininterrupto para assegurar o orçamento. São casais no início da vida, de até 40 anos, com dois ou três filhos e residindo em casas com até 5 cômodos construídos na área total do terreno.

Em transição, por que os bairros mais antigos estão passando por um processo de modificação da população, abrindo espaço para a chegada de pessoas de outras áreas da cidade em busca de terrenos maiores e bairro mais calmo, provavelmente. São profissionais liberais e técnicos das empresas do Distrito Industrial impondo um novo perfil de construções. Nos bairros mais recentes, especialmente no Residencial Orestes A. Giovanni, há a troca de posse e a conseqüente reforma, alterando o padrão original das construções em decorrência da chegada de outro tipo de morador.

O perfil educacional também indica que há um contingente de pessoas em fase de formação e não somente pessoas que tenham abandonado os estudos. De qualquer forma, reflete a condição de trabalho com baixo nível de qualificação, o que vem de encontro com a política de emprego das indústrias do Distrito Industrial, onde se aplicam 
as mais modernas técnicas de gerenciamento da produção, num caso típico de assimilação dos processos globalizantes da economia. No entanto, os efeitos da globalização sobre essa camada da população chegam como problema a ser enfrentado no dia-a-dia, com tanta margem de surpresa pelo que virá quanto pela certeza da volatilidade do posto de trabalho.

Tabela 2 - Atributos da paisagem na bacia hidrográfica do Ribeirão Claro, por setores.

\begin{tabular}{|c|c|c|c|}
\hline & $\begin{array}{l}\text { ALTO } \\
\text { CURSO }\end{array}$ & MÉDIO CURSO & $\begin{array}{l}\text { BAIXO } \\
\text { CURSO }\end{array}$ \\
\hline $\begin{array}{l}\text { Categoria/ } \\
\text { Setor }\end{array}$ & Ajapi & Rio Claro/São José & $\begin{array}{l}\text { Santa } \\
\text { Gertrudes }\end{array}$ \\
\hline $\begin{array}{ll}\text { Históricos } & \mathrm{e} \\
\text { arqueológicos }\end{array}$ & $\begin{array}{l}\text { Fazenda } \\
\text { Angélica }\end{array}$ & $\begin{array}{l}\text { Fazenda São José } \\
\text { Horto Florestal } \\
\text { - Museu do Eucalipto } \\
\text { - Solar de Navarro de } \\
\text { Andrade } \\
\text { - Solar da Faz. Santa } \\
\text { Gertrudes } \\
\text { Sítio arqueológico cerâmico } \\
\text { da PREMA } \\
\text { Sítio arqueológico cerâmico } \\
\text { da Vila Paulista } \\
\text { Sítio arqueológico lítico da } \\
\text { UNESP (?) }\end{array}$ & $\begin{array}{l}\text { Fazenda Santa } \\
\text { Gertrudes } \\
\text { Usina } \\
\text { Corumbataí } \\
\text { Matadouro } \\
\text { Municipal }\end{array}$ \\
\hline Geomorfológicos & Morro Grande & $\begin{array}{l}\text { Lagoas de topo } \\
\text { Ilha fluvial } \\
\text { Afloramento de sílex } \\
\text { Morro da Torre } \\
\text { Nascentes do Bosque da } \\
\text { Saúde nascente na área } \\
\text { verde do Recreio das Águas } \\
\text { Claras }\end{array}$ & $\begin{array}{l}\begin{array}{l}\text { Alagados } \\
\text { cavas } \\
\text { abandonadas }\end{array} \\
\begin{array}{l}\text { Erosões } \\
\text { boçorocas }\end{array}\end{array}$ \\
\hline Vegetação & $\begin{array}{l}\text { Fragmento de } \\
\text { mata ciliar no }\end{array}$ & $\begin{array}{l}\text { Fragmentos de floresta } \\
\text { estacional semidecidual da }\end{array}$ & \begin{tabular}{|lr} 
Bosque & do \\
manancial & João
\end{tabular} \\
\hline
\end{tabular}




\begin{tabular}{|c|c|c|c|}
\hline & $\begin{array}{l}\text { córrego do } \\
\text { Jacu } \\
\text { Fragmentos em } \\
\text { mata ciliar ao } \\
\text { longo da orla } \\
\text { do Ribeirão } \\
\text { Claro. }\end{array}$ & \begin{tabular}{|l||} 
Fazenda São José \\
Fragmentos de mata no \\
horto de Ajapi \\
Fragmentos de mata do \\
Recreio das Águas Claras
\end{tabular} & $\begin{array}{l}\text { Ramalho } \\
\text { Bosque da Saúde } \\
\text { Reserva legal da } \\
\text { Fazenda Santa } \\
\text { Gertrudes }\end{array}$ \\
\hline $\begin{array}{l}\text { Áreas } \\
\text { degradadas e/ou } \\
\text { exploradas }\end{array}$ & \begin{tabular}{|l||} 
Mineração \\
Mandu (areia)
\end{tabular} & \begin{tabular}{|l||} 
Jazida de argila de aluvião, \\
Horto Florestal
\end{tabular} & $\begin{array}{l}\text { Argila de aluvião } \\
\text { Caieiras } \\
\text { Pedreira de } \\
\text { diabásio } \\
\text { Aterro Sanitário }\end{array}$ \\
\hline Reflorestamentos & & $\begin{array}{l}\text { Seringueiras } \\
\text { Eucalipto } \\
\text { Mata ciliar do Ribeirão } \\
\text { Claro } \\
\text { Mata ciliar do córrego } \\
\text { Cachoeirinha } \\
\text { Mata ciliar do córrego da } \\
\text { Vila Cristina } \\
\end{array}$ & \\
\hline Áreas protegidas & \begin{tabular}{|l} 
Casarão \\
pedra do Grão \\
Mogol e seu \\
entorno \\
Mata ciliar \\
Lagoas de topo \\
APA \\
Piracicaba \\
Perímetro I
\end{tabular} & $\begin{array}{l}\text { Horto Florestal e } \\
\text { entorno } \\
\text { Sítio arqueológico } \\
\text { PREMA } \\
\text { Sítio arqueológico da } \\
\text { Paulista } \\
\text { Sítio arqua } \\
\text { UNESP (?) } \\
\text { Matas ciliares } \\
\text { Estação ferrovico da } \\
\text { entorno } \\
\text { APA Piracicaba Perímetro I }\end{array}$ & $\begin{array}{l}\text { Usina } \\
\text { Corumbataí } \\
\text { seu entorno } \\
\text { Matas ciliares }\end{array}$ \\
\hline Área & Horto de Ajapi $\|$ & Estação Ferroviária (F) & Complexo \\
\hline
\end{tabular}




\begin{tabular}{|c|c|c|c|}
\hline $\begin{array}{l}\text { propriedade } \\
\text { pública } \\
\text { Federal (F) } \\
\text { Estadual (E) } \\
\text { Municipal (M) }\end{array}$ & $\mid \begin{array}{ll}\text { e } & \text { Escola } \\
\text { Agrícola }(\mathrm{M})\end{array}$ & 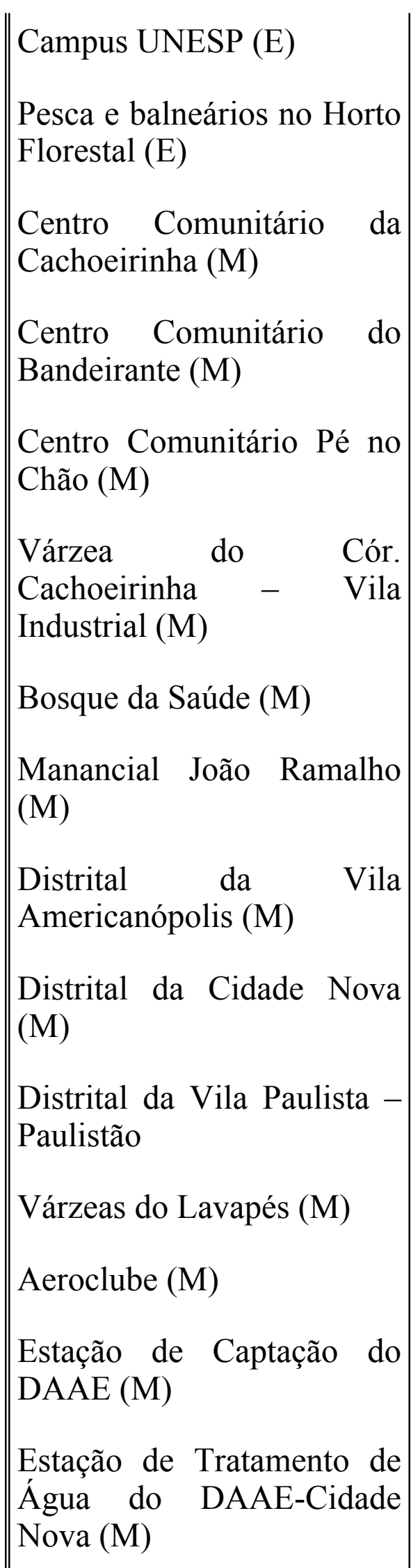 & $\begin{array}{l}\text { Aterro Sanitário } \\
\text { (M) }\end{array}$ \\
\hline $\begin{array}{l}\text { Áreas privadas } \\
\text { de } \quad \text { acesso } \\
\text { público real ou } \\
\text { potencial }\end{array}$ & \begin{tabular}{||lr||} 
Casarão & de \\
pedra do & Grão \\
Mogol & \\
& \\
Lagoa & do \\
Cacareco & $\mathrm{e}$
\end{tabular}$\|$ & \begin{tabular}{||l} 
Fazenda São José \\
Galpões da Mãe Preta \\
Erosões da Mãe Preta
\end{tabular} & \begin{tabular}{||l} 
Usina \\
Corumbataí \\
Fazenda Santa \\
Gertrudes
\end{tabular} \\
\hline
\end{tabular}




\begin{tabular}{|c|c|c|}
\hline outros & $\begin{array}{l}\text { Projeto Águas Claras } \\
\text { Grêmio da Bela Vista } \\
\text { Clube de Cavaleiros } \\
\text { "Victorino Machado" } \\
\text { Shopping Center Rio Claro } \\
\text { Orquidário Epiphânio } \\
\text { Loja Maçônica } \\
\text { Fazenda Pindorama } \\
\text { Fazenda Tunquelém } \\
\text { ASFAFI } \\
\text { Clube de Campo } \\
\text { AABB } \\
\text { Aeroclube }\end{array}$ & $\begin{array}{l}\text { Fazenda } \\
\text { Harmonia } \\
\text { Parque Cerâmico } \\
\text { Cava de basalto } \\
\text { Cava de argila } \\
\text { City gate do } \\
\text { gasoduto Bolívia } \\
\text { - Brasil }\end{array}$ \\
\hline
\end{tabular}

Fonte: SARTI, 2001, p. 238. 

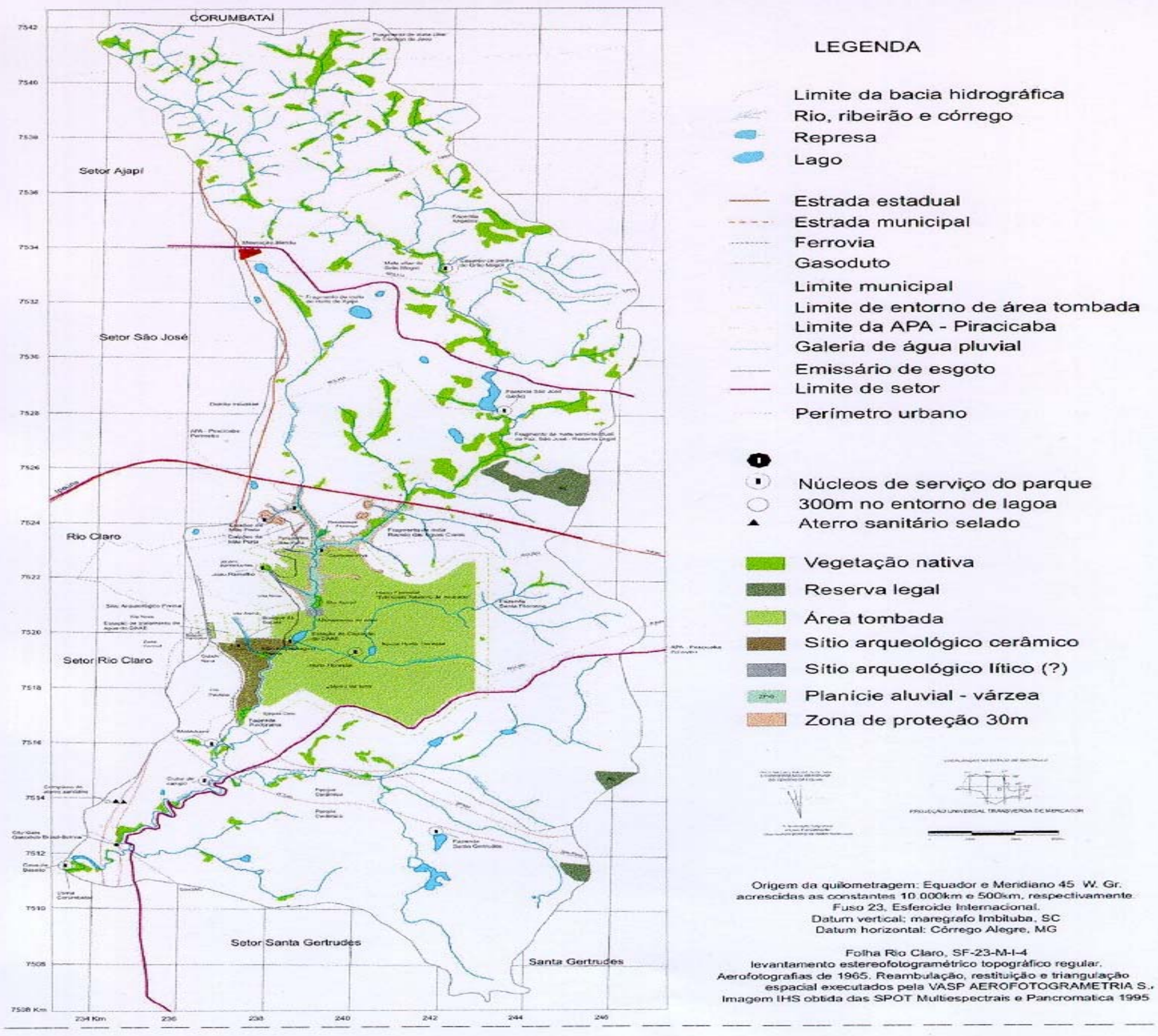

Click na Figura para Ampliar

Figura 2 - Mapa dos atributos da paisagem na bacia hidrográfica do Ribeirão Claro

As expressões de uso do tempo livre se restringem ao uso dos espaços livres mais próximos, aos eventos criados no âmbito das igrejas, qualquer que seja sua confissão. Mesmo quando a igreja deixa de ser a responsável direta pela atividade, as formas de uso desse tempo também estão sendo por ela comandadas. Católicos e evangélicos, os dois maiores grupos, desenvolvem trabalho voluntário nos templos e salões, hospitais e creches. Festas, somente as que a igreja promove, em detrimento até das familiares, que vão decaindo no hábito, talvez por exigirem espaço - o que as casas não têm - ou porque os custos sejam demasiadamente altos, mesmo quando modestos. 


\section{CONCLUSÕES}

Uma vez que a cidade moderna está construindo e trabalhando símbolos, condiciona que a estrutura do parque é morfologicamente discursiva, havendo intenções manifestas subjacentes a serem compreendidas e esclarecidas. Um parque moderno deve ser concebido e delimitado segundo as informações de que se dispõe, e segundo os recursos tecnológicos disponíveis para viabilizar a apropriação dessas informações. Assim como a cidade, é uma estrutura informacional.

A delimitação do parque deve considerar as áreas de instabilidade tais como meias-encostas, fazendo coincidir o seu limite com o de uma APA - Área de Proteção Ambiental em âmbito municipal, colocando-as sob controle mais rígido da sociedade e ensejando a adoção de uma política agressiva e sem condescendências de uso do solo para alterar positivamente a atual marca de $4,25 \%$ de cobertura vegetal nativa remanescente na bacia do Ribeirão Claro.

A instalação dos núcleos de serviço deve ser conduzida pelo diálogo e negociação com a comunidade, delineando-se a abrangência e a extensão das intervenções.

\section{REFERÊNCIAS}

BAKHTIN, M. A cultura popular na Idade Média e no Renascimento: o contexto de François Rebelais. 4 ed. São Paulo: Hucitec; Brasília: EdUnb, 1999. 419 p.

CAVALHEIRO, F.;DEL PICCHIA, P. C. D. Áreas verdes: conceitos, objetivos e diretrizes para o planejamento. In: ENCONTRO NACIONAL SOBRE ARBORIZAÇÃ̃ URBANA, 4, 1992, Vitória. Anais ... v. I. Vitória: 1992. p. 29-38.

DEAN, W. Rio Claro: um sistema brasileiro de grande lavoura - 1820-1920. Rio de Janeiro: Paz e Terra, 1977. 205 p.

FERRARA, L. D. A estratégia dos signos. São Paulo: Perspectiva, 1981. 197 p.

FOUCAULT, M. Microfísica do poder. 15 ed. Rio de Janeiro: Graal, 2000. 295p.

GOITIA, F. C. Breve história do urbanismo. 4 ed., Lisboa: Presença, 1996. 226 p.

JACOBS, J. Morte e vida de grandes cidades. São Paulo: Martins Fontes, 2000. 510 p.

MACHADO, P. A. L. Direito ambiental brasileiro. 7 ed. São Paulo: Malheiros, 1998. 
$894 \mathrm{p}$.

MAGNOLI, M. M. O parque no desenho urbano. In: TURKIENIKS, B.; MALTA, M. (orgs.) SEMINÁRIO SOBRE DESENHO URBANO NO BRASIL, 2, 1986, Brasília. Anais... São Paulo: Pini ; Brasília: CNPq ; Rio de Janeiro: FINEP, p. 112120, 1986.

MORIN, E. O método: a natureza da natureza. 3 ed., Mira-Sintra (PT): Europa-América, 1997. $363 \mathrm{p}$.

SANTOS, M. A natureza do espaço: técnica e tempo, razão e emoção. 3 ed. São Paulo: Hucitec, 1999. 308 p.

SARTI, A. C. Propostas para delimitação de um parque peri-urbano para a cidade de Rio Claro(SP).2001. 283f. Dissertação (Mestrado em Conservação e Manejo de Recursos) - Centro de Estudos Ambientais, Universidade Estadual Paulista, Rio Claro, 2001.

SCHAMA, S. Paisagem e memória. São Paulo: Cia. das Letras, 1996. 645p.

SEGAWA, H. Ao amor do público: jardins no Brasil. São Paulo: Nobel, 1996. 255 p.

SEVCENKO, N. A vitória-régia do Tâmisa. Folha de São Paulo, São Paulo, 21 jan.2000. Mais!, p.4-7.

SILVA, F. A. Informes preliminares sobre a arqueologia de Rio Claro. Belém:Museu Paraense Emílio Goeldi, 1967, Publicações Avulsas n. 6. p. 79-88.

THOMAS, K. O homem e o mundo natural. São Paulo: Cia. das Letras, 1996. 454 p. 